\title{
Reply
}

\section{Reply to letter from JG Schrama, R Rodenhuis and GC de Gast}

\author{
Bone Marrow Transplantation (2003) 31, 837. \\ doi:10.1038/sj.bmt.1703802
}

The analysis performed by Dr Schrama and colleagues of day 15 absolute lymphocyte count (ALC) recovery in metastatic breast cancer patients after autologous stem cell transplantation is important and appreciated, since it is the first evaluation of our findings ${ }^{1}$ by another group of investigators. Despite the fact that Dr Schrama's analysis does not demonstrate a survival difference between cohorts of patients achieving an ALC $\geqslant 500$ cells $/ \mu 1$ on day 15 posttransplant $v s$ those that do not (ALC $<500$ cells $/ \mu$ l cohort), we agree with Dr Schrama's conclusion that both our studies are too small to definitively ascertain the prognostic value of day 15 ALC. Appropriately powered, larger studies are required to ascertain the prognostic impact of day 15 ALC recovery in patients with metastatic breast cancer, as we had previously reported in patients with multiple myeloma and non-Hodgkin's lymphoma. ${ }^{2}$ Even though no difference in the median time to progression was observed in Dr. Schrama's account, it is interesting to point out that the survival curve for patients with ALC $\geqslant 500$ cells $/ \mu$ l appears to plateau compared with no plateau for patients with ALC $<500$ cells $/ \mu$ l.

Dr Schrama and colleagues also raised a very important question of the role of the reinfusion of lymphocytes on immune recovery and clinical outcome postautologous stem cell transplantation. We have recently submitted a manuscript on 550 patients describing the direct impact of the infused autograft ALC not only on immune recovery, but also on clinical outcome after autologous stem cell transplantation. This is relevant in view of our metastatic breast cancer data discussed herein, because some patients in that study were mobilized with growth factor alone and others with Flt-3 ligand. The different stem cell mobilization regimens may have an impact on different subsets of lymphocytes collected during stem cell harvests, possibly differentially affecting immune cell subset recovery and perhaps clinical outcome after autologous stem cell transplantation. Therefore, we agree with Dr Schrama and colleagues that further investigation on the role of immune system recovery on survival after autologous stem cell transplantation is warranted, and we wholeheartedly encourage their further work in this field.
LF Porrata

SN Markovic
Department of Internal Medicine, Division of Hematology, Mayo Clinic, 200 First Street SW, Rochester, MN 55905, USA

\section{References}

1 Porrata LF, Ingle JN, Litzow MR et al. Prolonged survival associated with early lymphocyte recovery after autologous hematopoietic stem cell transplantation for patients with metastatic breast cancer. Bone Marrow Transplant 2001; 28: 865-871.

2 Porrata LF, Gertz MA, Inwards DJ et al. Early lymphocyte recovery predicts superior survival after autologous hematopoietic stem cell transplantation in multiple myeloma or nonHodgkin’s lymphoma. Blood 2001; 98: 579-585.

\section{Erratum}

\section{Reply to letter from JG Schrama, R Rodenhuis and GC de Gast}

\author{
Bone Marrow Transplantation (2003) 31, 837. \\ doi:10.1038/sj.bmt.1704103
}

We would like to apologise that this reply was not included with the letter it refers to in volume 31 issue 2 . 